\title{
Modulation of iron metabolism in aging and in Alzheimer's disease: relevance of the choroid plexus
}

\author{
Sandro D. Mesquita ${ }^{1,2}$, Ana C. Ferreira ${ }^{1,2}$, João C. Sousa ${ }^{1,2}$, Nadine C. Santos ${ }^{1,2}$, \\ Margarida Correia-Neves ${ }^{1,2}$, Nuno Sousa ${ }^{1,2}$, Joana A. Palha ${ }^{1,2}$ and Fernanda Marques ${ }^{1,2}$ * \\ School of Health Sciences, Life and Health Sciences Research Institute (ICVS), University of Minho, Braga, Portugal \\ 2 ICVS/3B's-PT Government Associate Laboratory, Braga/Guimarães, Portugal
}

\author{
Edited by: \\ Andreas Frick, Institut National de la \\ Santé et de la Recherche Médicale, \\ France \\ Reviewed by: \\ Rafael Linden, Federal University of \\ Rio de Janeiro, Brazil \\ Barbara Wroblewska, Georgetown \\ University, USA \\ *Correspondence: \\ Fernanda Marques, School of Health \\ Sciences, Life and Health Sciences \\ Research Institute (ICVS), University \\ of Minho, Campus Gualtar, \\ 4710-057 Braga, Portugal. \\ e-mail: fmarques@ecsaude. \\ uminho.pt
}

Iron is essential for mammalian cellular homeostasis. However, in excess, it promotes free radical formation and is associated with aging-related progressive deterioration and with neurodegenerative disorders such as Alzheimer's disease (AD). There are no mechanisms to excrete iron, which makes iron homeostasis a very tightly regulated process at the level of the intestinal absorption. Iron is believed to reach the brain through receptor-mediated endocytosis of iron-bound transferrin by the brain barriers, the blood-cerebrospinal fluid (CSF) barrier, formed by the choroid plexus (CP) epithelial cells and the blood-brain barrier (BBB) formed by the endothelial cells of the brain capillaries. Importantly, the CP epithelial cells are responsible for producing most of the CSF, the fluid that fills the brain ventricles and the subarachnoid space. Recently, the finding that the CP epithelial cells display all the machinery to locally control iron delivery into the CSF may suggest that the general and progressive senescence of the CP may be at the basis of the impairment of regional iron metabolism, iron-mediated toxicity, and the increase in inflammation and oxidative stress that occurs with aging and, particularly, in AD.

Keywords: iron, choroid plexus, cerebrospinal fluid, aging, Alzheimer's disease

\section{INTRODUCTION}

Since iron deregulation is relevant for Alzheimer's disease (AD), in this review we focus on the relevance of iron metabolism regulation, particularly in the central nervous system (CNS). Iron accumulation occurs in specific brain areas that are affected in $\mathrm{AD}$ patients, such as the hippocampus and the cortex (Crichton et al., 2011). In these areas, iron and proteins that bind iron accumulate in the amyloid plaques (Silvestri and Camaschella, 2008; Leskovjan et al., 2011) and appear to play a role in the degree of tau phosphorylation (Egana et al., 2003). Furthermore, molecules that are directly or indirectly involved in the amyloidogenic pathway, such as amyloid precursor protein (APP) (Duce et al., 2010) and paired basic amino acid cleaving enzyme (PACE/furin) (Silvestri and Camaschella, 2008), have an ironrelated physiological function that depends on the brain iron levels. Iron access into the brain is modulated by the brain barriers, which have recently been proposed as active modulators of brain iron homeostasis (Moos et al., 2007; Marques et al., 2009a; Rouault et al., 2009). Here, we will focus mostly on the choroid plexus (CP), since several functions (and dysfunctions) of the CP, both in healthy and pathological conditions, may impact on the CNS mostly by influencing the composition of the cerebrospinal fluid (CSF). Overall, we intend to highlight how the barriers of the brain, as modulators of regional iron-homeostasis, can influence $\mathrm{AD}$ pathology.

\section{BODY IRON HOMEOSTASIS}

Iron is an essential element for cell metabolic processes and tissue homeostasis, since it is part of enzymes, cytochromes, and protein prosthetic groups. Although essential, deficiency or excess of iron can lead to pathological conditions such as anemia or hemochromatosis (HFE), respectively; therefore, iron metabolism must be tightly regulated. The main site of dietary iron absorption is the duodenum. Once within enterocytes, iron enters a common intracellular pool and is subsequently transferred across the basolateral surface into the bloodstream by the well characterized mammalian iron exporter ferroportin (FPN) (Graham et al., 2007). The released ferrous $\left(\mathrm{Fe}^{2+}\right)$ iron is then oxidized to ferric $\left(\mathrm{Fe}^{3+}\right)$ iron by hephaestin, a homolog of the serum ferroxidase ceruloplasmin, binds to circulating plasma transferrin (TF) and is subsequently taken up by cells through transferrin receptor 1 (TFR1)-mediated endocytosis (Graham et al., 2007).

The liver, particularly the hepatocyte, is the main site of iron deposition and storage (Anderson and Frazer, 2005). However, most of the body iron content exists in circulation inside erythrocytes. Within the cells, iron is incorporated into ferritin (composed by a heavy and a light chain, FTH and FTL). When the body is iron-replete, macrophages of the liver, spleen, bone marrow, and reticuloendothelial system can also store iron recovered from the phagocytosis of senescent erythrocytes. Inside the macrophage, iron is released from hemoglobin and can either be stored or released back into the circulation (Steele et al., 2005; Camaschella and Pagani, 2011). Depending on the intracellular iron levels, each cell regulates iron uptake mostly by modulating the expression of TFR1, while the efflux of iron through FPN is regulated systemically under the control of the liver-derived peptide hepcidin (HAMP) (Krause et al., 2000). Circulating HAMP binds FPN on the surface of enterocytes, 
macrophages, and other cell types causing its internalization and degradation (Ganz, 2011). Under physiological conditions the level of HAMP is regulated by body iron requirements via a complex cell signaling pathway that includes several cell membrane proteins such as HFE, transferrin receptor 2 (TFR2), and hemojuvelin (HJV) (Schmidt et al., 2008). Of interest, HAMP expression can also be modulated by proinflammatory cytokines such as interleukin-1 $\beta$ and -6 (IL-1 $\beta$ and IL-6), which are upregulated early during an inflammatory response (Lee et al., 2005).

Iron metabolism is impaired in several diseases where the level of specific iron-related proteins, such as HAMP or HFE, is low or absent. For example, in HFE, a disease characterized by mutations in the $H f e$ gene, HAMP production is impaired leading to a wide generalized iron overload in peripheral organs (Chua et al., 2004; Schmidt et al., 2008; Ganz and Nemeth, 2011). Interestingly, a striking observation is that the concentration of iron in the brain of mice with HFE appears to remain unaltered, despite the increase in circulating iron (Moos et al., 2000) and severe iron-overload in hepatocytes (Chua et al., 2004). These observations support the idea that the barriers of the brain may play an important role by preventing brain iron-overload (Rouault and Cooperman, 2006). However, in the context of several diseases in which iron accumulates in the CNS, such as AD (Duce et al., 2010), Parkinson's disease (Lei et al., 2012), or multiple sclerosis (Williams et al., 2012), the barriers of the brain appear to become progressively dysfunctional which is likely to impair their ability to regulate iron exchange between the periphery and the CNS. In fact, we recently showed that the $\mathrm{CP}$ epithelial cells, which compose the blood-CSF barrier (BCSFB), express all the genes known to participate in the modulation of iron homeostasis in the periphery, and therefore, seem well positioned to similarly regulate brain iron homeostasis (Marques et al., 2009a). However, little is known on how these may relate to neurodegenerative disorders.

\section{THE ROLE OF THE CP IN BRAIN IRON METABOLISM}

In all mammals, the CP is formed by a monolayer of epithelial cells that surround and enclose a central stroma. These epithelial cells are juxtaposed due to the apical localization of tight junctions (Engelhardt and Sorokin, 2009). The adult CP is highly irrigated by sinusoidal and fenestrated capillaries that are present in the inner stroma (Johansson et al., 2008; Wolburg and Paulus, 2010). The apical cytoplasmic membrane of the CP epithelial cells faces the CSF and contains numerous villosities, while the basolateral side faces the blood in the inner stroma, although indirectly, by contacting with the fenestrated capillaries (Emerich et al., 2005). Under physiological conditions, the CP epithelium forms a barrier that selectively restricts the access of molecules and blood circulating cells, from the stroma to the CSF and hence to the brain parenchyma (Engelhardt et al., 2001; Engelhardt and Sorokin, 2009). The CP is responsible for the secretion of the major components of the CSF and the transport of nutrients and trophic factors from the blood into the CSF (Figure 1) (Johanson et al., 2004). Moreover, the CP is involved in brain detoxification processes, by clearing several brain metabolites, such as amyloid beta $(A \beta)$ in the context of $A D$, from the CSF to the blood stream
(Carro et al., 2005; Vargas et al., 2010; Wolburg and Paulus, 2010).

Importantly, both the BCSFB and the blood-brain barrier (BBB) were shown to be two major sites of iron exchange between the periphery and the CNS. It is well-established that iron-loaded $\mathrm{TF}$ and its receptors are in part responsible for most of the iron content of the CNS. However, there are still some missing details concerning the mechanisms through which iron reaches the brain. In the BBB interface, holo-TF present in the circulating blood reaches the luminal surface of the endothelial cells and binds TFR1. The TF-receptor complex is internalized and, inside the endosome, the acidic environment leads to the release of the two $\mathrm{Fe}^{3+}$ particles from TF, which are thought to be reduced into $\mathrm{Fe}^{2+}$ by duodenal cytochrome B (DCYTB). The transport of $\mathrm{Fe}^{2+}$ from the endosomes into the cytosol of the endothelial cells remains controversial, due to absence of divalent metal transporter-1 (DMT1) expression in these cells (Moos et al., 2006). Nevertheless, $\mathrm{Fe}^{2+}$ is released into the cytosol and reaches the abluminal side of the endothelial cell (Moos et al., 2007), to be excreted out of the cell through FPN. Once in the brain side, ceruloplasmin, produced in astrocyte end-foot processes, oxidizes newly released $\mathrm{Fe}^{2+}$ to $\mathrm{Fe}^{3+}$, which again binds to TF (Benarroch, 2009) that is the main source of iron for neurons. Alternatively, $\mathrm{Fe}^{2+}$ can bind to low-molecular weight constituents, such as ATP and citrate that are present in the interstitial fluid in high concentrations and constitute an important source of iron to oligodendrocytes and astrocytes (Petroff et al., 1986; Montana et al., 2006). On the other hand, iron can be exported back into the interstitial fluid from astrocytes, oligodendrocytes, and neurons through FPN (Wu et al., 2004).

As mentioned, in addition to the endothelial cells, the cells that compose the BCSFB also play a crucial role in the modulation of regional iron levels, namely by the iron exchange between the blood and the CSF (Morris et al., 1992; Rouault et al., 2009). Similarly to endothelial cells, CP epithelial cells express TFR1 in the basolateral membrane, which binds to TF-bound iron arriving from the blood stream, inducing its internalization (Morris et al., 1992). Iron will then reach the cytosol of the epithelial cells following the TFR1 mechanism previously described that involves the endosomal proteins DMT1 and DCYTB (Figure 2) (Rouault et al., 2009). Moreover, the presence of FPN in the apical membrane of CP epithelial cells (Figure 2) (Wu et al., 2004) leads to the release of iron into the CSF, where it circulates bound to TF. Of notice, CP epithelial cells express other iron-related proteins under physiological conditions, namely HJV, HFE, TFR2, FTH, FTL, hephaestin, and ceruloplasmin (Figure 2) (Rouault and Cooperman, 2006; Rouault et al., 2009).

In a mouse model of peripheral inflammation, the $\mathrm{CP}$ was shown to rapidly respond also under adverse conditions, acting as an immune sensor for the brain (Marques et al., 2007, 2009b). Surprisingly, as early as one hour after peripheral administration of bacterial lipopolysaccharide (LPS), the up-regulation of IL-1 $\beta$ and TNF $\alpha$ gene expression is observed in the CP (Quan et al., 1998, 1999; Marques et al., 2007). Both proinflammatory molecules are able to modulate the expression of iron-related proteins, such as HAMP, whose expression was similarly found increased (Marques et al., 2009a). Additionally, the analysis of the 


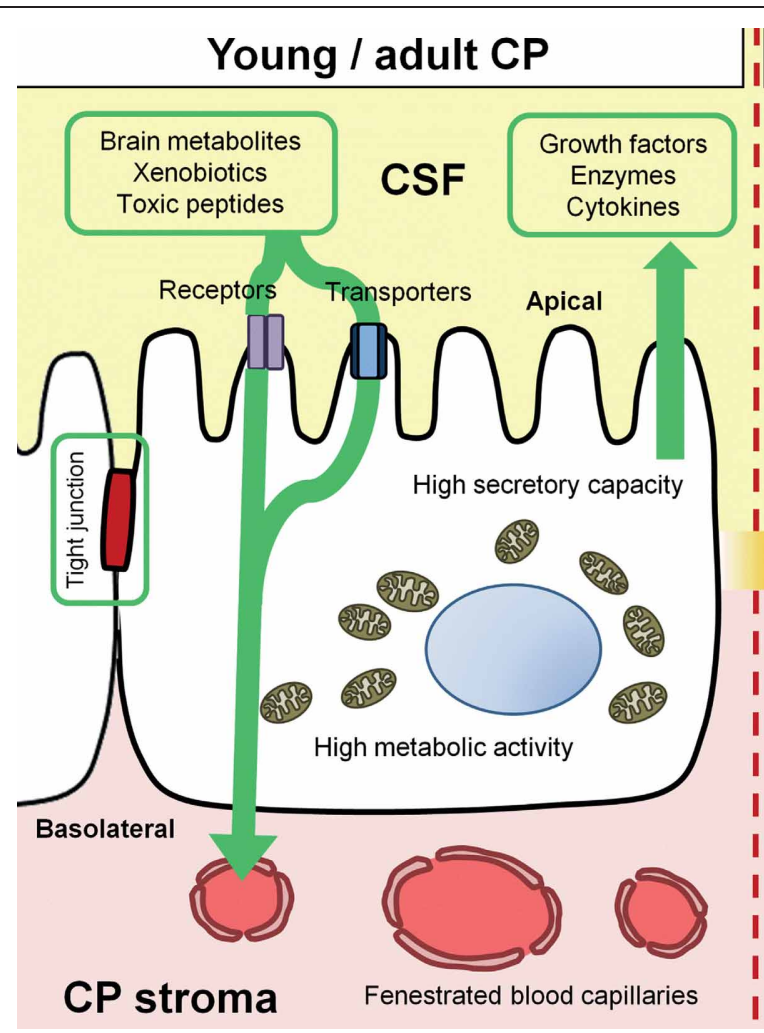

FIGURE 1 | The choroid plexus (CP) epithelial cells' morphology and architecture present a progressive decline throughout the aging process. These features are aggravated in Alzheimer's
Aged / AD CP

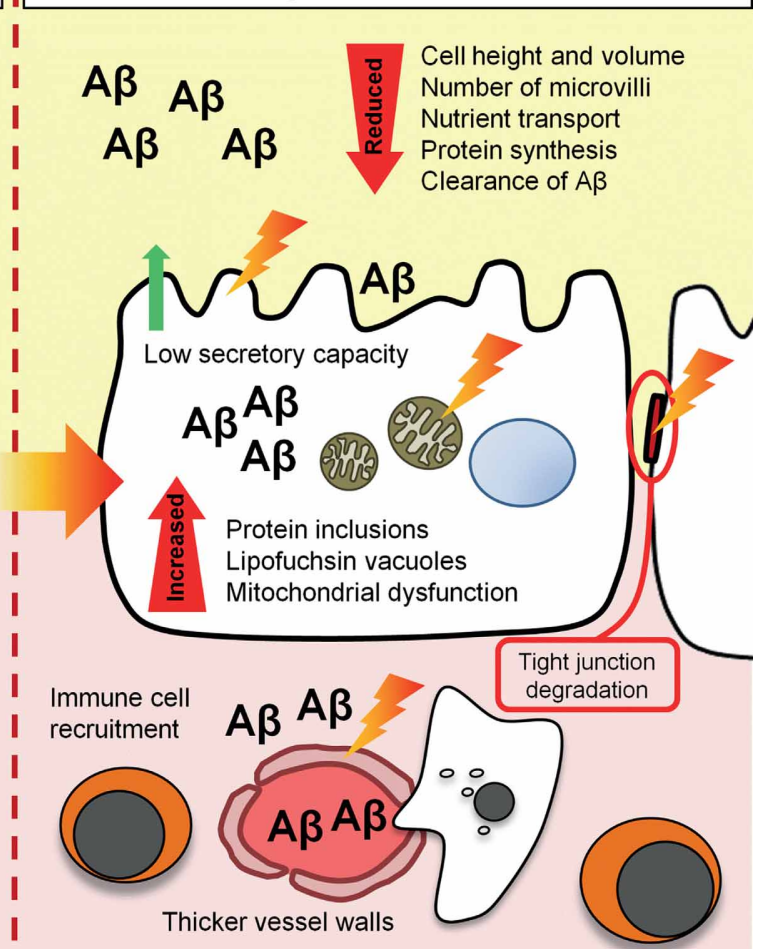

disease $(A D)$ and relate with increased oxidative stress and inflammation and decrease nutrient transport and secretion into the cerebrospinal fluid (CSF).
CP's transcriptome in response to the peripheral LPS injection revealed that the most up-regulated gene encodes for lipocalin 2 (LCN2), an increase that is similarly reflected in the CSF protein concentration (Marques et al., 2008). LCN2 is an acute phase protein initially found in neutrophil granules (Kjeldsen et al., 1993) and later described as a liver acute phase protein (Liu and Nilsen-Hamilton, 1995). LCN2 is also an iron-related protein since it is able to sequester bacterial iron-loaded siderophores and, therefore, participate in the mammalian innate immune response by limiting iron availability for bacteria (Sunil et al., 2007). However, in light of the recent discovery of an endogenous mammalian siderophore (Devireddy et al., 2010), and also since LCN2 requires catechol to bind and transport iron in the blood (Bao et al., 2010), it became clear that LCN2 can have an important physiological role, which is not completely unraveled, and may include iron uptake and release by cells that express LCN2 receptors, namely $24 \mathrm{p} 3 \mathrm{R}$. Additionally, other reports have implicated different roles for LCN2 in various cell types, namely as a protective protein against oxidative stress (Roudkenar et al., 2011), as a mitogen (Lee et al., 2009) and as an inducer of apoptosis (Devireddy et al., 2005). Despite these findings and the well-characterized role of LCN2 in neutrophils and in response to infection, its role in the CNS remains poorly explored. Still, recent studies have suggested LCN2 participation in processes such as inflammation, astrogliosis, and cell migration in the brain (Lee et al., 2009, 2011; Rathore et al., 2011), and also anxious (Mucha et al., 2011) and cognitive behaviors (Choi et al., 2011).

Altogether, the ability of the CP to rapidly respond to peripheral inflammatory stimuli by modulating the expression of ironrelated proteins such as HAMP and LCN2 (Marques et al., 2009b,c) may be relevant when addressing aging or agingassociated diseases such as $\mathrm{AD}$, where an increased in the basal level of peripheral proinflammatory molecules is observed in the absence of infection (Villeda et al., 2011) and iron seems to play a crucial role in the development and progression of the disease (Duce and Bush, 2010).

\section{WHY IRON AND AD?}

$\mathrm{AD}$ is a neurodegenerative disease characterized by two main brain pathological hallmarks: the formation of extracellular senile plaques, resulting from $A \beta$ peptide deposition, and the presence of neurofibrillary tangles composed by intracellular hyperphosphorylated tau. It is thought that much of the early pathological events in $\mathrm{AD}$ are due to the formation of dimeric and oligomeric forms of $A \beta$, which are formed through site-specific cleavage of APP (Walsh et al., 2005; Walsh and Selkoe, 2007) and accumulate in the brain. Importantly, $A \beta$ accumulation may result from decreased clearance of the $A \beta$ peptides through the barriers of the brain (Serot et al., 2003; Zlokovic, 2004; Crossgrove et al., 2005). Although the mechanisms that elicit the formation 


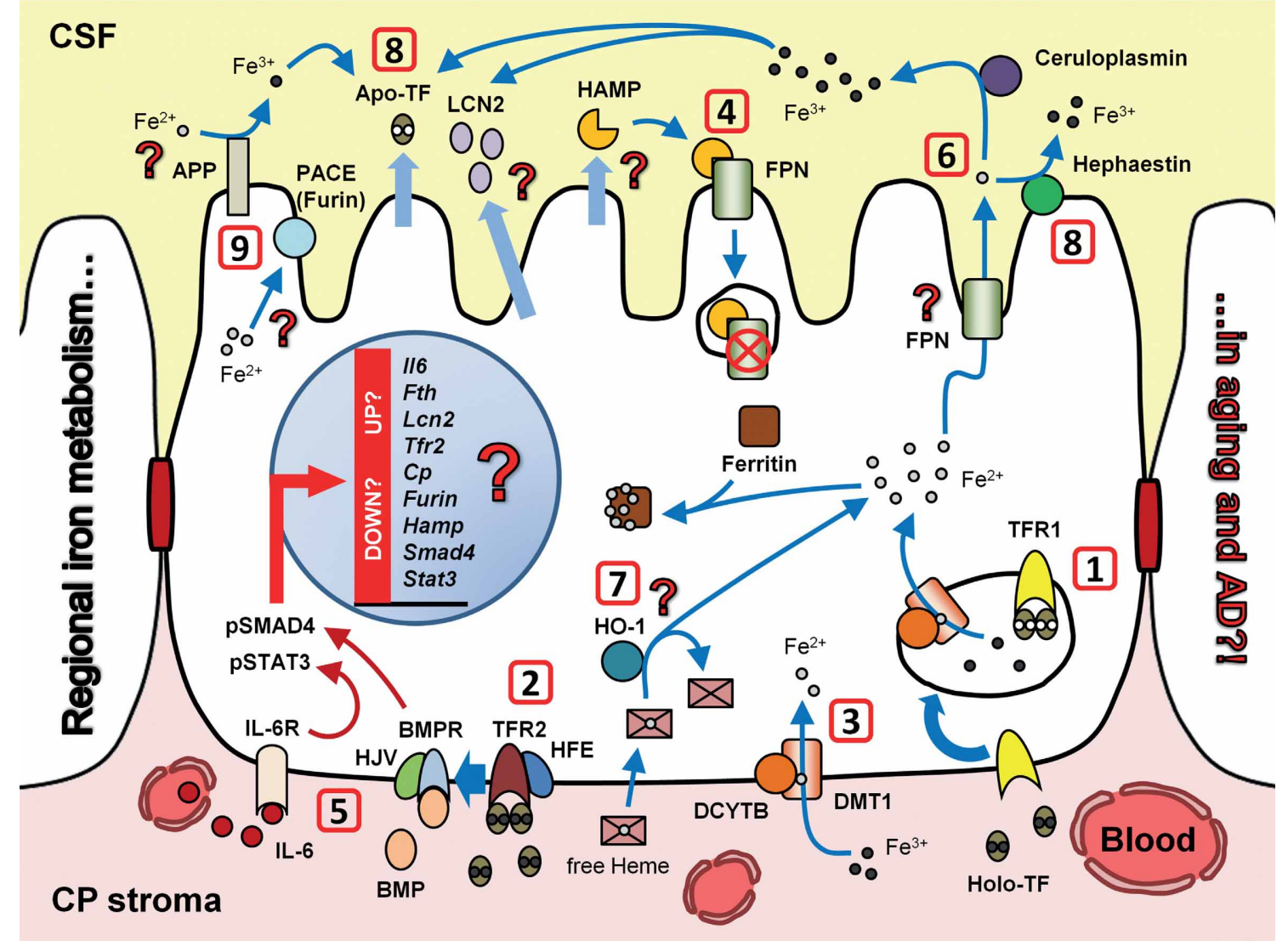

FIGURE 2 | The CP epithelial cells may participate in the regional regulation of brain iron metabolism due to the presence of specific membrane and secreted proteins. These epithelial cells express receptors that are directly or indirectly involved in iron uptake, such as transferrin receptors type 1 and 2 (TFR 1 and 2) (1) as well as

hemochromatosis (HFE) protein that is able to bind to TFR2; (2) Duodenal cytochrome B (DCYTB) and divalent metal transporter 1 (DMT1) are present in the basolateral membrane and, respectively, reduce ferric iron $\left(\mathrm{Fe}^{3+}\right)$ to ferrous iron $\left(\mathrm{Fe}^{2+}\right)$ and transport it into the cell; (3) An iron exporter localized in the apical face of the CP epithelial cell, ferroportin (FPN), can be internalized and degraded through the action of hepcidin (HAMP); (4) a hormone also produced by the $\mathrm{CP}$ in response to specific conditions, such as an inflammatory stimulus, through STAT3 and SMAD4 transcription factors. While the activation of STAT3 is likely to occur through IL-6, SMAD4 activation is probably mediated through the complex hemojuvelin (HJV)-bone morphogenetic protein (BMP)/SMAD4; (5) HAMP may then be secreted into the CSF and bind, in the apical side, to FPN and induce its internalization and degradation, therefore, preventing iron release into the CSF; (6) Heme oxygenase $1(\mathrm{HO}-1)$, which is expressed by the $\mathrm{CP}$, is an inducible oxygenase that has the ability to recycle heme, originating free $\mathrm{Fe}^{2+}$; (7) Additionally, the CP epithelial cells can also produce important peptides that are directly or indirectly involved in iron transport, oxidation, and storage, such as lipocalin 2 (LCN2), transferrin (TF), ceruloplasmin, ferritin, and hephaestin; (8) In the context of aging and AD, other important molecules, which are also expressed in the $\mathrm{CP}$, have recently been shown to be involved in iron homeostasis, like PACE/furin and amyloid precursor protein (APP); (9) Overall, changes in the expression of iron-related genes at the blood-CSF barrier may interfere with the level of iron in the brain and consequently trigger and/or aggravate aging and AD-related pathological events. of these toxic soluble agglomerates and, later on, insoluble fibrils and senile plaques are still poorly understood (Walsh and Selkoe, 2007; Querfurth and LaFerla, 2010), it is thought that free divalent metals such as iron, which give rise to strong oxidative radicals, maybe closely involved (Duce et al., 2010; Leskovjan et al., 2011; Liu et al., 2011).

Several observations in various cellular and animal models link iron and AD. For instance, APP, whose physiological function is still uncertain, was recently suggested to be up-regulated by iron and to favor the presence of iron deposits in amyloid plaques (Gaeta and Hider, 2005; Cahill et al., 2009). Indeed, an iron-responsive element (IRE) exists within the 5'-untranslated region of the APP transcript and this IRE allows iron to regulate the intracellular APP level the same way it regulates the transcription of genes that encode for FTH and FTL (Rogers et al., 2002). Additionally, the APP-IRE is also located up-stream of an IL-1 responsive domain (Rogers et al., 1999), which means that a proinflammatory stimulus may trigger APP gene expression. Importantly, APP was shown to have an iron-export ferroxidase activity (Duce et al., 2010). As a ferroxidase, APP participates in the export of iron from the cells, by mediating the oxidation of $\mathrm{Fe}^{2+}$ into $\mathrm{Fe}^{3+}$ (Duce et al., 2010). APP shares similarities with other ferroxidases, such as FTH and ceruloplasmin, being its activity inhibited by zinc and not by copper, a resembling feature of FTH but not of ceruloplasmin. However, APP is similar to ceruloplasmin since it interacts with FPN in order to export 
iron out of cells, a fact that was shown in a study using human embryonic kidney 293T cells that do not express ceruloplasmin (Duce et al., 2010). Moreover, in vivo experiments have shown that APP-null mice fed with an iron-rich diet have decreased $\mathrm{Fe}^{2+}$ efflux and increased iron accumulation inside brain cells, as well as a higher percentage of protein carbonylation and lower level of glutathione in the brain and liver (Duce et al., 2010).

Another interesting observation is that PACE, which is responsible for the activation of $\beta$-secretase involved in the amyloidogenic pathway, is positively modulated by iron uptake. High cellular iron content indirectly favors the formation of amyloidogenic peptides in $\mathrm{AD}$, through the activation of PACE (Silvestri and Camaschella, 2008). Moreover, one of the products of the enzymatic action of PACE is soluble hemojuvelin (sHJV) (Silvestri et al., 2008), which was shown to compete with membrane HJV (mHJV) for bone morphogenetic protein (BMP) signaling. Since BMP signaling can lead to the up-regulation of Hamp (Babitt et al., 2006), namely in CP epithelial cells (Figure 2) (Marques et al., 2009a), the activity of PACE may indirectly modulate the expression of Hamp in the brain.

The influence of excessive brain iron on the toxicity of $A \beta$ peptides and fibrils in $\mathrm{AD}$ is, in part, explained by the effect of this metal on the formation of oxidative hydroxyl radicals (Rival et al., 2009). By increasing the levels of the intracellular iron binding protein, ferritin, it was possible to rescue the phenotype associated with deposition of $\mathrm{A} \beta$ in a Drosophila fly model (Rival et al., 2009), which was correlated with a decreased level of protein carbonylation. Recently, iron was also linked to the aggregation process of $A \beta$ (Liu et al., 2011). The presence of $\mathrm{Fe}^{3+}$ during the aggregation process of $A \beta$ monomers into fibrils was shown to impede, later on, the fusion of fibrils into the less toxic amyloid deposits and to favor the stabilization of more toxic intermediate forms of $A \beta$. Toxic $A \beta$ intermediates originated by $\mathrm{Fe}^{3+}$ do not interact with thioflavin $\mathrm{T}$ and their final structure is less ordered, which delays the formation of senile plaques. Importantly, the formation of fibrils in the presence of iron was shown to lead to increased apoptosis in a neuronal cell line (Liu et al., 2011). In accordance, metal chelation with clioquinol (that sequesters iron, copper, and zinc) was shown to increase the lifespan of flies overexpressing $A \beta_{1-42}$ (Rival et al., 2009), to improve the cognitive performance and to reduce brain amyloid load in a mouse model of $\mathrm{AD}$ (Grossi et al., 2009).

\section{THE SENESCENT CP: IMPLICATIONS IN AGING AND IN AD}

The senescence of the CP is a gradual aging process. Aged CP epithelial cells present a general atrophy when compared to the adult CP (Figure 1). The epithelial cells display a decrease in height, total volume (Serot et al., 2000) and length of the apical microvilli (Serot et al., 2003). A striking deterioration of the CP epithelial cells is observed in AD (Wen et al., 1999; Johanson et al., 2004); the basement membrane, stroma, and blood vessel walls of the $\mathrm{CP}$ become thicker with age and acquire an irregular form in AD (Serot et al., 2000; Preston, 2001; Johanson et al., 2004). The accumulation of $A \beta_{1-40}$ and $A \beta_{1-42}$ peptides in CP epithelial cells (Figure 1) is, to a great extent, responsible for an increased level of oxidative stress and cell death (Vargas et al., 2010). Additionally, the extracellular deposition of $A \beta$ in the apical membrane, near the tight junctions, further enhances the disruption of the BCSFB (Figure 1) (Marco and Skaper, 2006; Vargas et al., 2010). The barrier properties of the CP progressively decay, which becomes leakier (Chalbot et al., 2011). In addition, its ability to secrete $A \beta$-carrier proteins and to express important receptors that scavenge amyloidogenic peptides was shown to decrease with age and to be compromised in several models of $\mathrm{AD}$ (Figures 1 and 3) (Zlokovic et al., 1996; Crossgrove et al., 2005; Antequera et al., 2009). A decreased activity of enzymes involved in oxidative phosphorylation (Preston, 2001) and mitochondrial respiratory chain, such as cytochrome $\mathrm{C}$ oxidase (Emerich et al., 2005), may also contribute to the impaired protein synthesis in the CP. This decrease in the metabolic activity of CP epithelial cells is in part correlated with $A \beta$-induced mitochondrial dysfunction (Figure 1) (Cornford et al., 1997; Vargas et al., 2010). These harmful events that damage the CP's morphology and architecture (Figure 1), together with a massive and extensive fibrosis observed in the central stroma and the surroundings of the $\mathrm{CP}$, are also responsible for the deficits in molecular exchanges between the CP and the CSF (Johanson et al., 2004). Moreover, the CP's capacity to promote the flow and the renewal of the CSF also declines with age and in AD (Preston, 2001; Redzic et al., 2005; Johanson et al., 2008).

The decrease in protein secretion and renewal of the CSF may be involved in the initiation and progression of $\mathrm{AD}$. As mentioned, some $\mathrm{CP}$ proteins are known to interact with $\mathrm{A} \beta$ and this could be in the basis of $A \beta$ clearance. One of such proteins is transthyretin (TTR), which is the major protein synthesized and secreted by the CP into the CSF (Dickson et al., 1986) and has been shown to bind and stabilize soluble A $\beta$ (Li et al., 2000; Tang et al., 2004) (Figure 3). Of interest, the absence of TTR in the mouse has been shown to accelerate the aging-associated cognitive decline (Sousa et al., 2007) and is associated with anxious behavior (Sousa et al., 2004). Additionally, transgenic mice that overexpress mutated forms of human APP and presenilin 1 , and comprise hemizigous deletions for the TTR gene, present an accelerated deposition of $A \beta$ in the hippocampus and cortex (Doggui et al., 2010) and increased $A \beta$-toxicity in the hippocampus when compared to control mice (Choi et al., 2007). These features appear to be directly involved with the decreased level of TTR in the brain. Moreover, decreased level of TTR in the CSF has been reported in patients with severe dementia and in AD (Riisoen, 1988; Serot et al., 1997), but some controversy subsists regarding the levels and functions of TTR in the brain and in cognition (Wati et al., 2009).

Other two important proteins produced and secreted by the $\mathrm{CP}$ are insulin growth factors 1 and 2 (IGF-1 and -2). Both are relevant in the context of AD (Preston, 2001; Emerich et al., 2005 ) since they seem to modulate the clearance of $A \beta$ from the $\mathrm{AD}$ brain (Figure 3). Importantly, the presence of IGF-1 in the CSF stimulates CP epithelial cells to express megalin/LRP-2 and to secrete $A \beta$-binding proteins that are recognized by megalin, namely TTR and clusterin, which favor the transport of these $\mathrm{A} \beta$ complexes from the brain into the blood (Figure 3) (Carro et al., 2002; Carro and Torres-Aleman, 2004). Shutting down the IGF-1 receptor signaling pathway in the CP was shown to exacerbate $\mathrm{AD}$ brain pathology in a mouse model (Carro et al., 2006) 


\section{Brain parenchyma}

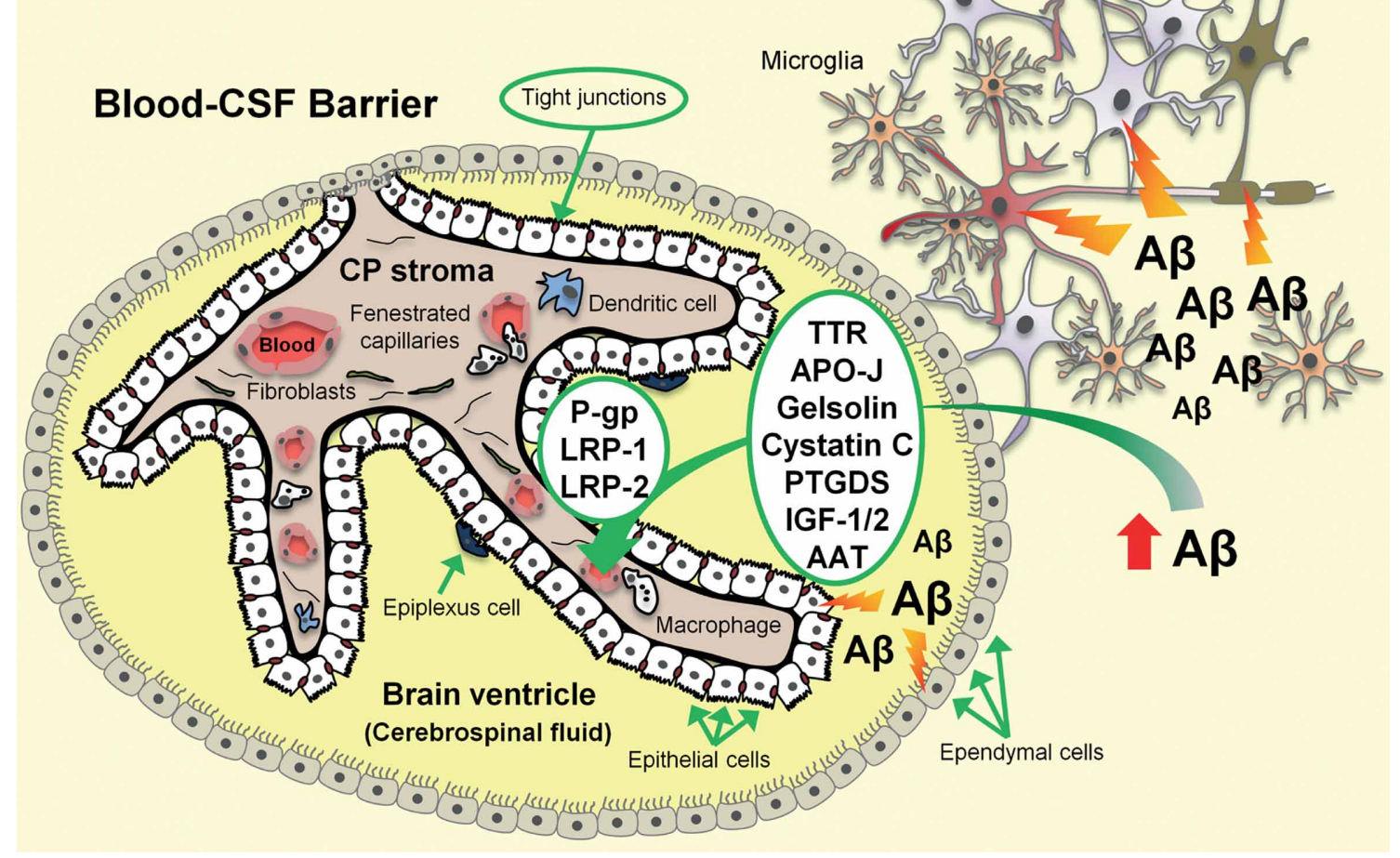

FIGURE 3 | A strong interaction is observed between the different cells that compose the blood-CSF barrier and the cells from the brain parenchyma. In the context of aging and $A D$, the development and progression of the disease strongly depends on the formation of different size amyloid beta $(A \beta)$ oligomers that deposit in the brain and are highly toxic. In order to prevent this, the CP epithelial cells secrete peptides to the CSF, which have the ability to bind, sequester, and remove $A \beta$ peptides, from the brain and CSF into the blood stream, through specific receptors present in the apical membrane (AAT, alpha 1 antitrypsin; APO-J, apolipoprotein-J/clusterin; IGF-1/2, insulin-like growth factor 1/2; P-gp, P-glycoprotein; PTGDS, prostaglandin D2 synthase; LRP-1/2, low density lipoprotein receptor-related protein-1/2; TTR, transthyretin). and silencing the expression of insulin and insulin-like growth factors in the brain was linked to increased levels of APP, gliosis, and lower level of acetylcholine (Carro et al., 2002; Rivera et al., 2005). Interestingly, two studies performed with samples from $\mathrm{AD}$ patients point to increased levels of IGF-1 (Salehi et al., 2008) and IGF-2 (Tham et al., 1993) in the serum and CSF, which indicate that controversy still remains.

Whilst these observations implicate dysfunction of the BCSFB regarding the modulation of $A \beta$ sequestration and clearance in aging and in $\mathrm{AD}$, available data also suggest a role of the barriers in iron deregulation and oxidative stress, as it will next be addressed.

\section{IS THE AGED BLOOD-CSF BARRIER CONTRIBUTING FOR IRON DEREGULATION WITHIN THE BRAIN?}

In models of aging and $\mathrm{AD}$, the $\mathrm{CP}$ was shown to contribute for the increase in reactive oxygen and nitrogen species observed in the brain. This increase in oxidative stress may, to some extent, be connected to an increased iron concentration, which in itself may lead to the formation of reactive species through the Fenton's reaction (Kell, 2009). However, a central question remains to be answered in the AD brain: whether CP epithelial cells accumulate iron in excess, as an attempt to protect the brain parenchyma, or present some sort of deficit regarding the transport of iron out of the brain. A hypothetical increase in intracellular iron in CP epithelial cells may prevent the correct functioning of enzymes involved in the mitochondrial respiratory chain, which could be one of the causes for increased mitochondrial stress and cell apoptosis, shown to occur in the CP from patients with AD (Vargas et al., 2010). Moreover, in AD, besides the formation of reactive species and protein carbonylation, traditional markers of oxidative stress are up-regulated in CP epithelial cells, namely heat shock protein-90 and heme oxygenase-1 (HO-1) (Anthony et al., 2003). HO-1 in particular is directly involved in iron-metabolism, since it recycles heme, therefore, releasing free iron and contributing to increased levels of intracellular iron (Figure 2). Surprisingly, a high expression of APP was shown to inhibit HO-1 and HO-2 activity and to accentuate free heme and possibly free iron neuronal toxicity (Takahashi et al., 2000).

Besides oxidative stress, inflammation is another process that is closely associated with the brain iron levels. As mentioned before, it has been recently suggested that increased levels of peripheral inflammation can induce a response in the $\mathrm{CP}$ and influence 
iron-metabolism (Marques et al., 2007, 2009a,b). As early as $3 \mathrm{~h}$ after peripheral LPS administration, the expression of Il-6 and Hamp is significantly up-regulated in the mouse CP (Figure 2) (Marques et al., 2009a). Taking this feature of the CP epithelial cells into account, it is plausible that the $\mathrm{CP}$ is functioning in the brain as a regulator of iron-metabolism when an inflammatory environment is established. It would be of great interest to know if that is the case in aging and in $\mathrm{AD}$, since it is recognized that the levels of proinflammatory cytokines in the blood increase with age (Villeda et al., 2011), which can influence the secretion of iron-metabolism-related proteins, such as HAMP, by CP epithelial cells. A recent study has shown that increased peripheral markers of inflammation, measured in the blood of aged subjects, do not correlate with increased levels of blood circulating HAMP or low iron status in the brain (Ferrucci et al., 2010); however, nothing is known concerning the levels of HAMP in the brain cells or CSF of aged individuals. On the other hand, IL-6, that is able to trigger the cell's STAT3 signaling pathway, appears to be associated to old-age anemia and is over-expressed in the aged mouse brain in response to LPS (Chen et al., 2008). Since IL-6 was shown to participate in the regulation of the expression of Hamp, not only in the liver (Lee et al., 2005) but also in the CP (Marques et al., 2009a) of adult mice, it remains to be assessed if the CP contributes to the level of IL-6 in the aged brain (Figure 2). Moreover, the CP is able to up-regulate genes that encode for iron-related proteins and transcription factors, such as Tfr2, Fth, Cp (ceruloplasmin), Stat3, and Smad4 (Figure 2), in conditions of peripheral inflammation, and these may contribute to regional regulation of iron in the CNS (Marques et al., 2009a). In aging and in $\mathrm{AD}$, however, the pattern of expression of these genes by the CP is still unknown.

Altogether, the aging process is accompanied by increasing levels of inflammation and oxidative stress, both in the periphery and in the brain, which can elicit changes in the CP's capacity to regulate iron metabolism and to impact on the initiation and progression of brain pathology in AD.

\section{REFERENCES}

Anderson, G. J., and Frazer, D. M. (2005). Hepatic iron metabolism. Semin. Liver Dis. 25, 420-432.

Antequera, D., Vargas, T., Ugalde, C., Spuch, C., Molina, J. A., Ferrer, I., Bermejo-Pareja, F., and Carro, E. (2009). Cytoplasmic gelsolin increases mitochondrial activity and reduces Abeta burden in a mouse model of Alzheimer's disease. Neurobiol. Dis. 36, 42-50.

Anthony, S. G., Schipper, H. M., Tavares, R., Hovanesian, V., Cortez, S. C., Stopa, E. G., and Johanson, C. E. (2003). Stress protein expression in the Alzheimer-diseased choroid plexus. J. Alzheimers Dis. 5, 171-177.

Babitt, J. L., Huang, F. W., Wrighting, D. M., Xia, Y., Sidis, Y., Samad, T. A., Campagna, J. A., Chung, R. T., Schneyer, A. L., Woolf, C. J.,

\section{CONCLUDING REMARKS}

The CP, as a secretory tissue, influences the composition of the CSF and, therefore, the brain milieu. Brain faculties progressively decline with aging and are severely affected in AD. Age-dependent alterations at the level of the BCSFB may impact on the pathological events that take place in the $\mathrm{AD}$ brain. Additionally, recent studies strongly suggest that alterations in iron metabolism and iron-related proteins can impact on initiation and progression of $\mathrm{AD}$ pathology. Since the barriers of the brain can act as important regulators of iron metabolism, it is timely to investigate how they impact on brain homeostasis in aging and in AD. The senescent-aged/AD CP epithelial cells may present alterations in the expression of iron-carrier proteins and their receptors, such as LCN2 and 24p3R or TF and TFR1, or in proteins involved in iron export and storage, like HAMP, FPN, and FTH (Figure 2) that will strongly influence iron homeostasis in the mammalian brain. A dysregulation of the level of iron in the brain will enhance the amyloidogenic pathway and potentiate the aggregation and toxicity of $A \beta$ which, together with a decreased excretion of $A \beta$ through the $\mathrm{CSF} / \mathrm{CP} / \mathrm{BBB}$ (Figure 3) may impact on the progression of brain pathology in $\mathrm{AD}$. We believe that the modulation of the CP's function in this context can be a new potential therapeutic target to prevent or delay the rapid aging and decay of the brain in AD. Importantly, progressive aging-related changes in the transcriptome and secretome of CP epithelial cells may be associated with the diagnosis and prognosis of $\mathrm{AD}$, and may eventually lead to the discovery of reliable markers of $\mathrm{AD}$ initiation and progression.

\section{ACKNOWLEDGMENTS}

Sandro D. Mesquita and Ana C. Ferreira are recipients of fellowships from the Fundação para a Ciência e Tecnologia (FCT, Portugal). Fernanda Marques and Nadine C. Santos are recipients of postdoctoral fellowships by the Fundação para a Ciência e Tecnologia (FCT, Portugal) and the Switchbox project (European Commission FP7 initiative grant HEALTH-F2-2010-259772), respectively.

iron and inflammation in neurodegenerative diseases. Biochim. Biophys. Acta 1790, 615-628.

Camaschella, C., and Pagani, A. (2011). Iron and erythropoiesis: a dual relationship. Int. J. Hematol. 93, 21-26.

Carro, E., Spuch, C., Trejo, J. L., Antequera, D., and Torres-Aleman, I. (2005). Choroid plexus megalin is involved in neuroprotection by serum insulin-like growth factor I. J. Neurosci. 25, 10884-10893.

Carro, E., and Torres-Aleman, I. (2004) The role of insulin and insulin-like growth factor I in the molecular and cellular mechanisms underlying the pathology of Alzheimer's disease. Eur. J. Pharmacol. 490, 127-133.

Carro, E., Trejo, J. L., Gomez-Isla, T., LeRoith, D., and Torres-Aleman, I. (2002). Serum insulin-like growth factor I regulates brain amyloid-beta levels. Nat. Med. 8, 1390-1397.
Carro, E., Trejo, J. L., Spuch, C., Bohl, D., Heard, J. M., and TorresAleman, I. (2006). Blockade of the insulin-like growth factor I receptor in the choroid plexus originates Alzheimer's-like neuropathology in rodents: new cues into the human disease? Neurobiol. Aging 27, 1618-1631.

Chalbot, S., Zetterberg, H., Blennow, K., Fladby, T., Andreasen, N., Grundke-Iqbal, I., and Iqbal, K. (2011). Blood-cerebrospinal fluid barrier permeability in Alzheimer's disease. J. Alzheimers Dis. 25, 505-515.

Chen, J., Buchanan, J. B., Sparkman, N. L., Godbout, J. P., Freund, G. G., and Johnson, R. W. (2008). Neuroinflammation and disruption in working memory in aged mice after acute stimulation of the peripheral innate immune 
system. Brain Behav. Immun. 22, 301-311.

Choi, J., Lee, H. W., and Suk, K. (2011). Increased plasma levels of lipocalin 2 in mild cognitive impairment. J. Neurol. Sci. 305, 28-33.

Choi, S. H., Leight, S. N., Lee, V. M., Li, T., Wong, P. C., Johnson, J. A., Saraiva, M. J., and Sisodia, S. S. (2007). Accelerated abeta deposition in APPswe/PS1deltaE9 mice with hemizygous deletions of TTR (transthyretin). J. Neurosci. 27, 7006-7010.

Chua, A. C., Olynyk, J. K., Leedman, P. J., and Trinder, D. (2004). Nontransferrin-bound iron uptake by hepatocytes is increased in the Hfe knockout mouse model of hereditary hemochromatosis. Blood 104, 1519-1525.

Cornford, E. M., Varesi, J. B., Hyman, S., Damian, R. T., and Raleigh, M. J. (1997). Mitochondrial content of choroid plexus epithelium. Exp. Brain Res. 116, 399-405.

Crichton, R. R., Dexter, D. T., and Ward, R. J. (2011). Brain iron metabolism and its perturbation in neurological diseases. J. Neural. Transm. 118, 301-314.

Crossgrove, J. S., Li, G. J., and Zheng, W. (2005). The choroid plexus removes beta-amyloid from brain cerebrospinal fluid. Exp. Biol. Med. (Maywood) 230, 771-776.

Devireddy, L. R., Gazin, C., Zhu, X., and Green, M. R. (2005). A cell-surface receptor for lipocalin $24 \mathrm{p} 3$ selectively mediates apoptosis and iron uptake. Cell 123, 1293-1305.

Devireddy, L. R., Hart, D. O., Goetz, D. H., and Green, M. R. (2010). A mammalian siderophore synthesized by an enzyme with a bacterial homolog involved in enterobactin production. Cell 141, 1006-1017.

Dickson, P. W., Aldred, A. R., Marley, P. D., Bannister, D., and Schreiber, G. (1986). Rat choroid plexus specializes in the synthesis and the secretion of transthyretin (prealbumin). Regulation of transthyretin synthesis in choroid plexus is independent from that in liver. J. Biol. Chem. 261, 3475-3478.

Doggui, S., Brouillette, J., Chabot, J. G., Farso, M., and Quirion, R. (2010). Possible involvement of transthyretin in hippocampal beta-amyloid burden and learning behaviors in a mouse model of Alzheimer's disease (TgCRND8). Neurodegener. Dis. 7, 88-95.

Duce, J. A., and Bush, A. I. (2010). Biological metals and Alzheimer's disease: implications for therapeutics and diagnostics. Prog. Neurobiol. 92, 1-18.

Duce, J. A., Tsatsanis, A., Cater, M. A., James, S. A., Robb, E., Wikhe, K., Leong, S. L., Perez, K., Johanssen, T., Greenough, M. A., Cho, H. H., Galatis, D., Moir, R. D., Masters, C. L., McLean, C., Tanzi, R. E., Cappai, R., Barnham, K. J., Ciccotosto, G. D., Rogers, J. T., and Bush, A. I. (2010). Iron-export ferroxidase activity of beta-amyloid precursor protein is inhibited by zinc in Alzheimer's disease. Cell 142, 857-867.

Egana, J. T., Zambrano, C., Nunez, M. T., Gonzalez-Billault, C., and Maccioni, R. B. (2003). Ironinduced oxidative stress modify tau phosphorylation patterns in hippocampal cell cultures. Biometals 16, 215-223.

Emerich, D. F., Skinner, S. J., Borlongan, C. V., Vasconcellos, A. V., and Thanos, C. G. (2005). The choroid plexus in the rise, fall and repair of the brain. Bioessays 27, 262-274.

Engelhardt, B., and Sorokin, L. (2009). The blood-brain and the blood-cerebrospinal fluid barriers: function and dysfunction. Semin. Immunopathol. 31, 497-511.

Engelhardt, B., Wolburg-Buchholz, K., and Wolburg, H. (2001). Involvement of the choroid plexus in central nervous system inflammation. Microsc. Res. Tech. 52, 112-129.

Ferrucci, L., Semba, R. D., Guralnik, J. M., Ershler, W. B., Bandinelli, S., Patel, K. V., Sun, K., Woodman, R. C., Andrews, N. C., Cotter, R. J., Ganz, T., Nemeth, E., and Longo, D. L. (2010). Proinflammatory state, hepcidin, and anemia in older persons. Blood 115, 3810-3816.

Gaeta, A., and Hider, R. C. (2005). The crucial role of metal ions in neurodegeneration: the basis for a promising therapeutic strategy. $\mathrm{Br}$. J. Pharmacol. 146, 1041-1059.

Ganz, T. (2011). Hepcidin and iron regulation, 10 years later. Blood 117, 4425-4433.

Ganz, T., and Nemeth, E. (2011). Hepcidin and disorders of iron metabolism. Annu. Rev. Med. 62, 347-360.

Graham, R. M., Chua, A. C., Herbison, C. E., Olynyk, J. K., and Trinder, D. (2007). Liver iron transport. World J. Gastroenterol. 13, 4725-4736.

Grossi, C., Francese, S., Casini, A., Rosi, M. C., Luccarini, I., Fiorentini, A., Gabbiani, C., Messori, L., Moneti, G., and Casamenti, F. (2009). Clioquinol decreases amyloidbeta burden and reduces working memory impairment in a transgenic mouse model of Alzheimer's disease. J. Alzheimers Dis. 17, 423-440.

Johanson, C., McMillan, P., Tavares, R., Spangenberger, A., Duncan, J., Silverberg, G., and Stopa, E. (2004). Homeostatic capabilities of the choroid plexus epithelium in Alzheimer's disease. Cerebrospinal Fluid Res. 1, 3.

Johanson, C. E., Duncan, J. A. 3rd, Klinge, P. M., Brinker, T., Stopa, E. G., and Silverberg, G. D. (2008). Multiplicity of cerebrospinal fluid functions: new challenges in health and disease. Cerebrospinal Fluid Res. 5,10 .

Johansson, P. A., Dziegielewska, K. M., Liddelow, S. A., and Saunders, N. R. (2008). The blood-CSF barrier explained: when development is not immaturity. Bioessays 30 , 237-248.

Kell, D. B. (2009). Iron behaving badly: inappropriate iron chelation as a major contributor to the aetiology of vascular and other progressive inflammatory and degenerative diseases. BMC Med. Genomics 2, 2.

Kjeldsen, L., Johnsen, A. H., Sengelov, H., and Borregaard, N. (1993). Isolation and primary structure of NGAL, a novel protein associated with human neutrophil gelatinase. J. Biol. Chem. 268, 10425-10432.

Krause, A., Neitz, S., Magert, H. J., Schulz, A., Forssmann, W. G., Schulz-Knappe, P., and Adermann, K. (2000). LEAP-1, a novel highly disulfide-bonded human peptide, exhibits antimicrobial activity. FEBS Lett. 480, 147-150.

Lee, S., Kim, J. H., Seo, J. W., Han, H. S., Lee, W. H., Mori, K., Nakao, K., Barasch, J., and Suk, K. (2011). Lipocalin-2 Is a chemokine inducer in the central nervous system: role of chemokine ligand 10 (CXCL10) in lipocalin-2-induced cell migration. J. Biol. Chem. 286, 43855-43870.

Lee, S., Park, J. Y., Lee, W. H., Kim, H., Park, H. C., Mori, K., and Suk, K. (2009). Lipocalin-2 is an autocrine mediator of reactive astrocytosis. $J$. Neurosci. 29, 234-249.

Lee, P., Peng, H., Gelbart, T., Wang, L., and Beutler, E. (2005). Regulation of hepcidin transcription by interleukin-1 and interleukin-6. Proc. Natl. Acad. Sci. U.S.A. 102, 1906-1910.

Lei, P., Ayton, S., Finkelstein, D. I., Spoerri, L., Ciccotosto, G. D., Wright, D. K., Wong, B. X., Adlard, P. A., Cherny, R. A., Lam, L. Q., Roberts, B. R., Volitakis, I., Egan, G. F., McLean, C. A., Cappai, R., Duce,
J. A., and Bush, A. I. (2012). Tau deficiency induces parkinsonism with dementia by impairing APPmediated iron export. Nat. Med. 18, 291-295.

Leskovjan, A. C., Kretlow, A., Lanzirotti, A., Barrea, R., Vogt, S., and Miller, L. M. (2011). Increased brain iron coincides with early plaque formation in a mouse model of Alzheimer's disease. Neuroimage 55, 32-38.

Li, M. D., Kane, J. K., Matta, S. G., Blaner, W. S., and Sharp, B. M. (2000). Nicotine enhances the biosynthesis and secretion of transthyretin from the choroid plexus in rats: implications for betaamyloid formation. J. Neurosci. 20, 1318-1323.

Liu, B., Moloney, A., Meehan, S., Morris, K., Thomas, S. E., Serpell, L. C., Hider, R., Marciniak, S. J., Lomas, D. A., and Crowther, D. C. (2011). Iron promotes the toxicity of amyloid beta peptide by impeding its ordered aggregation. J. Biol. Chem. 286, 4248-4256.

Liu, Q., and Nilsen-Hamilton, M. (1995). Identification of a new acute phase protein. J. Biol. Chem. 270, 22565-22570.

Marco, S., and Skaper, S. D. (2006). Amyloid beta-peptide1-42 alters tight junction protein distribution and expression in brain microvessel endothelial cells. Neurosci. Lett. 401, 219-224.

Marques, F., Falcao, A. M., Sousa, J. C., Coppola, G., Geschwind, D., Sousa, N., Correia-Neves, M. and Palha, J. A. (2009a). Altered iron metabolism is part of the choroid plexus response to peripheral inflammation. Endocrinology 150, 2822-2828.

Marques, F., Rodrigues, A. J., Sousa, J. C., Coppola, G., Geschwind, D. H., Sousa, N., Correia-Neves, M., and Palha, J. A. (2008). Lipocalin 2 is a choroid plexus acute-phase protein. J. Cereb. Blood Flow Metab. 28, 450-455.

Marques, F., Sousa, J. C., Coppola, G., Falcao, A. M., Rodrigues, A. J., Geschwind, D. H., Sousa, N., Correia-Neves, M., and Palha, J. A. (2009b). Kinetic profile of the transcriptome changes induced in the choroid plexus by peripheral inflammation. J. Cereb. Blood Flow Metab. 29, 921-932.

Marques, F., Sousa, J. C., Coppola, G., Geschwind, D. H., Sousa, N., Palha, J. A., and Correia-Neves, M. (2009c). The choroid plexus response to a repeated peripheral inflammatory stimulus. BMC Neurosci. 10, 135 
Marques, F., Sousa, J. C., CorreiaNeves, M., Oliveira, P., Sousa, N., and Palha, J. A. (2007). The choroid plexus response to peripheral inflammatory stimulus. Neuroscience 144, 424-430.

Montana, V., Malarkey, E. B., Verderio, C., Matteoli, M., and Parpura, V. (2006). Vesicular transmitter release from astrocytes. Glia 54, 700-715.

Moos, T., Rosengren Nielsen, T., Skjorringe, T., and Morgan, E. H. (2007). Iron trafficking inside the brain. J. Neurochem. 103, 1730-1740.

Moos, T., Skjoerringe, T., Gosk, S., and Morgan, E. H. (2006). Brain capillary endothelial cells mediate iron transport into the brain by segregating iron from transferrin without the involvement of divalent metal transporter 1. J. Neurochem. 98, 1946-1958.

Moos, T., Trinder, D., and Morgan, E. H. (2000). Cellular distribution of ferric iron, ferritin, transferrin and divalent metal transporter 1 (DMT1) in substantia nigra and basal ganglia of normal and beta2-microglobulin deficient mouse brain. Cell. Mol. Biol. (Noisyle-grand) 46, 549-561.

Morris, C. M., Keith, A. B., Edwardson, J. A., and Pullen, R. G. (1992). Uptake and distribution of iron and transferrin in the adult rat brain. J. Neurochem. 59, 300-306.

Mucha, M., Skrzypiec, A. E., Schiavon, E., Attwood, B. K., Kucerova, E., and Pawlak, R. (2011). Lipocalin-2 controls neuronal excitability and anxiety by regulating dendritic spine formation and maturation. Proc. Natl. Acad. Sci. U.S.A. 108, 18436-18441.

Petroff, O. A., Yu, R. K., and Ogino, T. (1986). High-resolution proton magnetic resonance analysis of human cerebrospinal fluid. $J$. Neurochem. 47, 1270-1276.

Preston, J. E. (2001). Ageing choroid plexus-cerebrospinal fluid system. Microsc. Res. Tech. 52, 31-37.

Quan, N., Stern, E. L., Whiteside, M. B., and Herkenham, M. (1999). Induction of pro-inflammatory cytokine mRNAs in the brain after peripheral injection of subseptic doses of lipopolysaccharide in the rat. J. Neuroimmunol. 93, 72-80.

Quan, N., Whiteside, M., and Herkenham, M. (1998). Time course and localization patterns of interleukin-1beta messenger RNA expression in brain and pituitary after peripheral administration of lipopolysaccharide. Neuroscience 83, 281-293.
Querfurth, H. W., and LaFerla, F. M. (2010). Alzheimer's disease. N. Engl. J. Med. 362, 329-344.

Rathore, K. I., Berard, J. L., Redensek, A., Chierzi, S., Lopez-Vales, R. Santos, M., Akira, S., and David, S. (2011). Lipocalin 2 plays an immunomodulatory role and has detrimental effects after spinal cord injury. J. Neurosci. 31, 13412-13419.

Redzic, Z. B., Preston, J. E., Duncan, J. A., Chodobski, A., and SzmydyngerChodobska, J. (2005). The choroid plexus-cerebrospinal fluid system: from development to aging. Curr. Top. Dev. Biol. 71, 1-52.

Riisoen, H. (1988). Reduced prealbumin (transthyretin) in CSF of severely demented patients with Alzheimer's disease. Acta Neurol. Scand. 78, 455-459.

Rival, T., Page, R. M., Chandraratna, D. S., Sendall, T. J., Ryder, E., Liu, B., Lewis, H., Rosahl, T., Hider, R., Camargo, L. M., Shearman, M. S., Crowther, D. C., and Lomas, D. A. (2009). Fenton chemistry and oxidative stress mediate the toxicity of the beta-amyloid peptide in a Drosophila model of Alzheimer's disease. Eur. J. Neurosci. 29, 1335-1347.

Rivera, E. J., Goldin, A., Fulmer, N., Tavares, R., Wands, J. R., and de la Monte, S. M. (2005). Insulin and insulin-like growth factor expression and function deteriorate with progression of Alzheimer's disease: link to brain reductions in acetylcholine. J. Alzheimers Dis. 8, 247-268.

Rogers, J. T., Leiter, L. M., McPhee, J. Cahill, C. M., Zhan, S. S., Potter, H., and Nilsson, L. N. (1999). Translation of the alzheimer amyloid precursor protein mRNA is upregulated by interleukin-1 through 5 '-untranslated region sequences. J. Biol. Chem. 274, 6421-6431.

Rogers, J. T., Randall, J. D., Cahill, C. M., Eder, P. S., Huang, X., Gunshin, H., Leiter, L., McPhee, J., Sarang, S. S., Utsuki, T., Greig, N. H., Lahiri, D. K., Tanzi, R. E., Bush, A. I., Giordano, T., and Gullans, S. R. (2002). An iron-responsive element type II in the 5'-untranslated region of the Alzheimer's amyloid precursor protein transcript. J. Biol. Chem. 277, 45518-45528.

Rouault, T. A., and Cooperman, S. (2006). Brain iron metabolism. Semin. Pediatr. Neurol. 13, 142-148.

Rouault, T. A., Zhang, D. L., and Jeong, S. Y. (2009). Brain iron homeostasis, the choroid plexus, and localization of iron transport proteins. Metab. Brain Dis. 24, 673-684.
Roudkenar, M. H., Halabian, R., Bahmani, P., Roushandeh, A. M., Kuwahara, Y., and Fukumoto, M. (2011). Neutrophil gelatinaseassociated lipocalin: a new antioxidant that exerts its cytoprotective effect independent on Heme Oxygenase-1. Free Radic. Res. $45,810-819$.

Salehi, Z., Mashayekhi, F., and Naji, M. (2008). Insulin like growth factor-1 and insulin like growth factor binding proteins in the cerebrospinal fluid and serum from patients with Alzheimer's disease. Biofactors 33, 99-106.

Schmidt, P. J., Toran, P. T., Giannetti, A. M., Bjorkman, P. J., and Andrews, N. C. (2008). The transferrin receptor modulates Hfe-dependent regulation of hepcidin expression. Cell Metab. 7, 205-214.

Serot, J. M., Bene, M. C., and Faure, G. C. (2003). Choroid plexus, aging of the brain, and Alzheimer's disease. Front. Biosci. 8, s515-s521.

Serot, J. M., Bene, M. C., Foliguet, B., and Faure, G. C. (2000). Morphological alterations of the choroid plexus in lateonset alzheimer's disease. Acta Neuropathol. 99, 105-108.

Serot, J. M., Christmann, D., Dubost, T., and Couturier, M. (1997) Cerebrospinal fluid transthyretin: aging and late onset alzheimer's disease. J. Neurol. Neurosurg. Psychiatry $63,506-508$.

Silvestri, L., and Camaschella, C. (2008). A potential pathogenetic role of iron in Alzheimer's disease. J. Cell. Mol. Med. 12, 1548-1550.

Silvestri, L., Pagani, A., and Camaschella, C. (2008). Furinmediated release of soluble hemojuvelin: a new link between hypoxia and iron homeostasis. Blood 111, 924-931.

Sousa, J. C., Grandela, C., FernandezRuiz, J., de Miguel, R., de Sousa, L., Magalhaes, A. I., Saraiva, M. J., Sousa, N., and Palha, J. A. (2004). Transthyretin is involved in depression-like behaviour and exploratory activity. J. Neurochem. 88, 1052-1058.

Sousa, J. C., Marques, F., Dias-Ferreira, E., Cerqueira, J. J., Sousa, N., and Palha, J. A. (2007). Transthyretin influences spatial reference memory. Neurobiol. Learn. Mem. 88, 381-385.

Steele, T. M., Frazer, D. M., and Anderson, G. J. (2005). Systemic regulation of intestinal iron absorption. IUBMB Life 57, 499-503.

Sunil, V. R., Patel, K. J., NilsenHamilton, M., Heck, D. E., Laskin, J. D., and Laskin, D. L. (2007).
Acute endotoxemia is associated with upregulation of lipocalin $24 \mathrm{p} 3 / \mathrm{Lcn} 2$ in lung and liver. Exp. Mol. Pathol. 83, 177-187.

Takahashi, M., Dore, S., Ferris, C. D., Tomita, T., Sawa, A., Wolosker H., Borchelt, D. R., Iwatsubo, T., Kim, S. H., Thinakaran, G., Sisodia, S. S., and Snyder, S. H. (2000). Amyloid precursor proteins inhibit heme oxygenase activity and augment neurotoxicity in Alzheimer's disease. Neuron 28, 461-473.

Tang, Y. P., Haslam, S. Z., Conrad, S. E., and Sisk, C. L. (2004). Estrogen increases brain expression of the mRNA encoding transthyretin, an amyloid beta scavenger protein. $J$. Alzheimers Dis. 6, 413-420. discussion 443-449.

Tham, A., Nordberg, A., Grissom, F. E., Carlsson-Skwirut, C., Viitanen, M., and Sara, V. R. (1993). Insulinlike growth factors and insulinlike growth factor binding proteins in cerebrospinal fluid and serum of patients with dementia of the Alzheimer type. J. Neural Transm. Park Dis. Dement. Sect. 5, 165-176.

Vargas, T., Ugalde, C., Spuch, C., Antequera, D., Moran, M. J., Martin, M. A., Ferrer, I., Bermejo-Pareja, F., and Carro, E. (2010). Abeta accumulation in choroid plexus is associated with mitochondrial-induced apoptosis. Neurobiol. Aging 31, 1569-1581.

Villeda, S. A., Luo, J., Mosher, K. I., Zou, B., Britschgi, M., Bieri, G., Stan, T. M., Fainberg, N., Ding, Z., Eggel, A., Lucin, K. M., Czirr, E., Park, J. S., Couillard-Despres, S., Aigner, L., Li, G., Peskind, E. R., Kaye, J. A., Quinn, J. F., Galasko, D. R., Xie, X. S., Rando, T. A., and Wyss-Coray, T. (2011). The ageing systemic milieu negatively regulates neurogenesis and cognitive function. Nature 477, 90-94.

Walsh, D. M., and Selkoe, D. J. (2007). A beta oligomers: a decade of discovery. J. Neurochem. 101, 1172-1184.

Walsh, D. M., Townsend, M., Podlisny, M. B., Shankar, G. M., Fadeeva, J. V., El Agnaf, O., Hartley, D. M., and Selkoe, D. J. (2005). Certain inhibitors of synthetic amyloid betapeptide (Abeta) fibrillogenesis block oligomerization of natural Abeta and thereby rescue long-term potentiation. J. Neurosci. 25, 2455-2462.

Wati, H., Kawarabayashi, T., Matsubara, E., Kasai, A., Hirasawa, T., Kubota, T., Harigaya, Y., Shoji, M., and Maeda, S. (2009). Transthyretin accelerates vascular Abeta deposition in a mouse model of Alzheimer's disease. Brain Pathol. $19,48-57$. 
Wen, G. Y., Wisniewski, H. M., and Kascsak, R. J. (1999). Biondi ring tangles in the choroid plexus of Alzheimer's disease and normal aging brains: a quantitative study. Brain Res. 832, 40-46.

Williams, R., Buchheit, C. L., Berman, N. E., and LeVine, S. M. (2012). Pathogenic implications of iron accumulation in multiple sclerosis. J. Neurochem. 120, 7-25.

Wolburg, H., and Paulus, W. (2010). Choroid plexus: biology and pathology. Acta Neuropathol. 119, 75-88.

Wu, L. J., Leenders, A. G., Cooperman, S., Meyron-Holtz, E., Smith, S., Land, W., Tsai, R. Y., Berger, U.
V., Sheng, Z. H., and Rouault, T. A. (2004). Expression of the iron transporter ferroportin in synaptic vesicles and the bloodbrain barrier. Brain Res. 1001, 108-117.

Zlokovic, B. V. (2004). Clearing amyloid through the bloodbrain barrier. J. Neurochem. 89, 807-811.

Zlokovic, B. V., Martel, C. L., Matsubara, E., McComb, J. G., Zheng, G., McCluskey, R. T., Frangione, B., and Ghiso, J. (1996). Glycoprotein 330/megalin: probable role in receptor-mediated transport of apolipoprotein $\mathrm{J}$ alone and in a complex with Alzheimer disease amyloid beta at the blood-brain and blood-cerebrospinal fluid barriers. Proc. Natl. Acad. Sci. U.S.A. 93, 4229-4234.

Conflict of Interest Statement: The authors declare that the research was conducted in the absence of any commercial or financial relationships that could be construed as a potential conflict of interest.

Received: 18 April 2012; paper pending published: 07 May 2012; accepted: 09 May 2012; published online: 22 May 2012.
Citation: Mesquita SD, Ferreira AC, Sousa JC, Santos NC, Correia-Neves M, Sousa N, Palha JA and Marques F (2012) Modulation of iron metabolism in aging and in Alzheimer's disease: relevance of the choroid plexus. Front. Cell. Neurosci. 6:25. doi: 10.3389/fncel. 2012.00025

Copyright (c) 2012 Mesquita, Ferreira, Sousa, Santos, Correia-Neves, Sousa, Palha and Marques. This is an openaccess article distributed under the terms of the Creative Commons Attribution Non Commercial License, which permits non-commercial use, distribution, and reproduction in other forums, provided the original authors and source are credited. 